\title{
O FOMENTO À PARTICIPAÇÃO POLÍTICA FEMININA E O CONTROLE DO JUS PUNIENDI ESTATAL: A LEI 13.831/2019 SOB A PERSPECTIVA DO DIREITO SANCIONADOR ELEITORAL
}

\author{
Promoting female political participation and control of jus state puniendi: federal \\ Law 13.831/2019 under the perspective of electoral sanctioning law
}

\author{
Amanda Guimarães da Cunha \\ Luiz Magno Pinto Bastos Junior
}

\begin{abstract}
Resumo: Para fomentar a participação feminina na política, o art. 44, inciso V, da Lei 9096/95, inserido pela Lei 12.034/09, impõe aos partidos políticos o dever de destinar 5\% dos recursos recebidos do Fundo Partidário para desenvolvimento de "programas de promoção e difusão da participação política das mulheres”. Essas regras foram alteradas pela Lei n. 13.165/15, que institucionalizou desestímulos à concretização desse mecanismo, autorizando que os recursos fossem utilizados no financiamento de candidaturas femininas ( $\mathbb{S} 5^{\circ}-\mathrm{A}$ e $7^{\circ}$ ). Tais autorizações foram declaradas inconstitucionais pelo STF na ADI n. 5.617/DF, que, entretanto, permitiu que esses mesmos recursos fossem utilizados na campanha de 2018. Com a promulgação da Lei n. 13.831/19, algumas regras de transição foram inseridas para regular os efeitos do descumprimento do repasse em questão (art. 55-A, 55-B e 55-C), as quais foram acusadas de promover uma "anistia geral" aos partidos políticos. Dessa forma, o objetivo deste trabalho consistiu em analisar se a promulgação dessas regras realmente acarretou uma "anistia", bem como se elas eram compatíveis com a ordem constitucional vigente. Chegou-se às conclusões de que as alterações promovidas nada mais fizeram do que cristalizar a decisão do STF (nos Embargos opostos em relação à ADI 5617) e, ainda, efetivar o entendimento jurisprudencial até então consolidado, em respeito aos valores da segurança jurídica e da preservação do devido processo legal, imprescindíveis em se tratando de exercício do jus puniendi do Estado, qualificado como direito sancionador eleitoral.
\end{abstract}

Palavras-chave: Participação feminina na política. Lei 13.831/2019. Fundo Partidário. Direito sancionador eleitoral.
Abstract: To foment female participation in politics, art. 44, item V, of Law 9096/95, inserted by Law $12.034 / 09$, imposes on political parties the obligation to allocate $5 \%$ of the funds received from the Party Subsidies for the development of "programs for the promotion and diffusion of women's political participation". These rules were changed by Law 13.165/15, which institutionalized disincentives to the implementation of this mechanism, authorizing the resources to be used to finance female applications ( $\mathbb{S} 5-\mathrm{A}$ and $7^{\circ}$ ). Such authorizations were declared unconstitutional by the STF in ADI 5.617/DF, which, however, allowed these same resources to be used in the 2018 electoral campaign. With the promulgation of Law 13.831/19, some transitional rules were introduced to regulate the effects of non-compliance with the transfer in question (art. 55-A, 55-B and 55-C), which were accused of promoting a "general amnesty" to political parties. Therefore, the aim of this paper was to analyze whether the promulgation of these rules really resulted in an "amnesty", as well as if they were compatible with the current constitutional order. The conclusion was that the alterations promoted did nothing but crystallize the STF's decision (in the opposing embargos in relation to ADI 5617) and, in addition, implement the previously consolidated jurisprudential understanding, respecting the values of legal certainty and the preservation of due legal process, indispensable when it comes to the exercise of the jus state puniendi, qualified as electoral sanctioning right.

Keywords: Female participation in politics. Law 13.831/2019. Party Subsidies. Electoral sanctioning right.

Artigo recebido em 22 jul. 2019 e aprovado em 6 ago. 2019. 


\section{Introdução}

As discussões acerca da necessidade de incremento da participação feminina na política estão na hora do dia, quer seja pelos constantes clamores dos movimentos que lutam para que haja a efetiva inserção das mulheres no espaço político, quer seja em razão da necessidade de que as agremiações partidárias implementem essas medidas sob pena de responsabilização em eventual descumprimento delas. A questão referente à necessidade de incremento do grau de participação das mulheres na política não somente se faz necessária em decorrência de simples previsão legal, mas reflete uma questão de equidade e de qualidade democrática.

As mulheres hoje compõem a maioria do eleitorado brasileiro, na faixa de 52,63\% do total, de acordo com ranking atualizado do Tribunal Superior Eleitoral (TSE) de 2019, mas sua representatividade está distante de refletir a mesma proporção. Segundo levantamento do Projeto Mulheres Inspiradoras, que cruzou dados do TSE e do Banco Mundial, o Brasil ocupa a 161ª posição, dentre 186 países, no que diz respeito à presença de mulheres no Executivo (PMI, 2018) ${ }^{1}$. Por seu turno, em relação ao Parlamento, de acordo com a organização Inter-Parliamentary Union, o Brasil ocupa a $133^{a}$ posição, num ranking de 190 países (IPU, 2019)².

Desde a década de 90, algumas ações afirmativas têm sido implementadas no país, mas os seus resultados concretos têm sido pífios. O Congresso Nacional tem adotado um posicionamento ambivalente, com avanços e recuos legislativos no tocante à sua implementação. Além do que os próprios partidos políticos, por vezes, adotam soluções criativas voltadas a resolver o problema da inclusão das mulheres que, de acordo com a narrativa de muitas greis partidárias, não gostam de se envolver na política partidária.

Este artigo trata de uma dessas políticas, qual seja, a regra que impõe aos partidos políticos o dever de destinarem 5\% (cinco por cento) da totalidade dos recursos recebidos do Fundo Partidário para o desenvolvimento de "programas de promoção e difusão da participação política das mulheres" (art. 44, inc. V, instituído pela Lei n. 12.034/2005 na Lei 9096/95).

\footnotetext{
${ }^{1}$ Essa porcentagem foi calculada tendo como base a representatividade feminina nas chefias de Governo e de Estado, o número e a proporção de habitantes governados por mulheres; e a proporção de cargos em ministérios ocupados por lideranças do sexo feminino.

${ }^{2} \mathrm{O}$ monitoramento realizado pela IPU leva em consideração apenas o número de mulheres nos parlamentos nacionais.
} 
A recalcitrância dos partidos políticos em conferirem plena concretude a essa imposição legal e os desafios decorrentes do fim do financiamento empresarial das eleições (em face da finalização do julgamento da ADI 4650/DF por parte do STF) concorreram para a promulgação da Lei n. 13.165, de 29.9.2015, que, a pretexto de "incentivar a participação feminina", instituiu um conjunto de elementos que, na prática, atuaram como fatores de desestímulo aos partidos políticos para que estes cumprissem a exigência legal.

Uma das alterações determinadas por esse diploma diz respeito à autorižacãa legal prevista nos $\mathbb{\$} 5^{\mathrm{Q}}-\mathrm{A}$ e $7^{\mathrm{a}}$ para que os recursos previstos no art. 44, inc. V, da Lei dos Partidos Políticos fossem destinados ao financiamento de candidaturas femininas nas eleições subsequentes (a despeito de sua finalidade legal).

Essa regra permissiva foi declarada inconstitucional (por arrastamento) pelo Supremo Tribunal Federal que, nos autos da ADI n. 5.617/DF, não somente afastou os limites impostos pelo art. 9 da Lei n. 13.165/2015 (que fixava um limite de 5 a 15\% dos recursos do fundo partidário destinado às campanhas eleitorais), mas exigiu que os partidos políticos destinassem, no mínimo, $30 \%$ (trinta por cento) desses recursos às candidaturas femininas a partir das eleições de 2018.

Por fim, em 17.6.2019, foi promulgada a Lei n. 13.831 que, entre outras temáticas, criou regras de transição destinadas a regular os efeitos do descumprimento por parte das agremiações partidárias da regra prevista no art. 44, inc. V, da Lei 9096/95. Trata-se dos artigos 55-A, 55-B e 55-C que, por força do art. $2^{\circ}$ do novo diploma, foram acrescentados ao título das Disposições Finais e Transitórias da referida lei.

Essas regras foram duramente criticadas em diversas manifestações públicas porque, pretensamente, estariam instituindo uma espécie de anistia geral aos partidos políticos que vinham sistematicamente descumprindo-a. E, mais ainda, em relação ao art. 55-C, ter-se-ia representado uma flagrante reação do Parlamento à mudança jurisprudencial levada à efeito pelo Tribunal Superior Eleitoral quando, em abril de 2019, passou a sancionar as agremiações partidárias que descumprissem as exigências constantes do art. 44 , inc. V com a reprovação de suas contas.

Diante do cenário descrito, o objetivo deste artigo consiste em analisar se a promulgação das referidas regras efetivamente importou na 
propalada anistia geral aos partidos políticos inadimplentes e, por conseguinte, se as regras de transição criadas (arts. 55-A, 55-B e 55-C) são compatíveis com o ordenamento constitucional vigente.

A pesquisa adotou como método de investigação o método dedutivo, em face do qual a análise sobre a legitimidade da criação das referidas regras de transição foi feita tendo como referência que a aplicação de sanção aos partidos políticos por descumprimento de comando legal se insere no âmbito do direito administrativo sancionador e, como tal, exige a estrita observância do devido processo legal e a proteção da segurança jurídica que se expressa, entre outras garantias, na aplicação do princípio da aplicação da lei (e interpretação judicial) mais benéfica ao agente sancionado.

$\mathrm{Na}$ primeira seção, é feito um breve levantamento dos primeiros mecanismos de ação afirmativa voltados à inclusão das mulheres na política até a promulgação da Lei n. 12.034/2009, com especial ênfase na criação da exigência de destinação de recursos do fundo partidário para a instituição de programas de fomento à participação feminina na política (art. 44, inc. V, da Lei n. 9096/95). E, ainda, é feita uma análise crítica sobre a institucionalização dos desestímulos à sua utilização pelas greis, sendo estes previstos pelas alterações introduzidas pela Lei n. 13.165/2015.

$\mathrm{Na}$ seção seguinte, é feita análise sobre o alcance dos comandos normativos previstos nos artigos 55-A, 55-B e 55-C acrescidos à Lei dos Partidos Políticos pela Lei n. 13.831/2019, qualificando-os como regras de transição em face da declaração de inconstitucionalidade dos $\iint 5^{\circ}-\mathrm{A}$ e 7응 da LPP (incluídos pela Lei n. 13.165/2015) e da guinada jurisprudencial levada a efeito pelo TSE no tocante ao regime de sancionamento por descumprimento do mecanismo previsto no art. 44, inc. V, da Lei n. 9096/95 (fomento aos programas de participação feminina).

$\mathrm{Na}$ última seção, é especificamente analisada a legitimidade das regras instituídas e, tendo em vista o seu enquadramento como direito sancionador eleitoral, defende-se que as mesmas, com o sentido que lhes é atribuído neste artigo, nada mais representam do que uma concretização da garantia constitucional da segurança jurídica e da necessidade de que as normas mais gravosas devam ser aplicadas prospectivamente, inclusive quando o agravamento da regra decorrer de mudança jurisprudencial, nos termos do art. 24 da Lei de Introdução ao Direito Brasileiro. 
Nas conclusões, é enfrentado o argumento dirigido contra as referidas regras (de que elas importariam uma anistia geral a partidos infratores) e são sintetizadas as conclusões parciais discutidas no trabalho, chamando a atenção para o fato de que, em se tratando de direito sancionador, deve-se assegurar aos sancionados um conjunto de garantias de defesa, tendo em vista que jamais se pode perder de vista que representa uma faceta do exercício do jus puniendi estatal.

\section{Políticas de ação afirmativa e a "evolução" histórica da previsão de destinação de recursos do fundo partidário a programas de fomento da participação feminina}

As políticas de ação afirmativa para fomentar a participação política da mulher ganharam lugar na agenda nacional após a IV Conferência Internacional sobre a Mulher, de 1995, realizada pela Organização das Nações Unidas em Pequim. Nesta Conferência paradigmática, todos os países que lá se reuniram, entre os quais o Brasil, comprometeram-se a adotar mecanismos destinados ao fomento da ampliação da participação das mulheres nos órgãos governamentais dos países signatários ${ }^{3}$.

\footnotetext{
${ }^{3}$ 190. Medidas que os governos devem adotar: a) comprometer-se a estabelecer a meta de equilíbrio entre mulheres e homens nos organismos e comitês governamentais, assim como nas entidades da administração pública e no judiciário, incluídas, entre outras coisas, a fixação de objetivos específicos e medidas de implementação, a fim de aumentar substancialmente o número de mulheres e alcançar uma representação de paridade das mulheres e dos homens, se necessário mediante ação afirmativa em favor das mulheres, em todos os postos governamentais e da administração pública; b) adotar medidas, inclusive, quando apropriado, nos sistemas eleitorais, para estimular os partidos políticos a incorporarem as mulheres a postos públicos eletivos e não eletivos, na mesma proporção e nas mesmas categorias que os homens; c) defender e promover a igualdade de direitos das mulheres e dos homens em matéria de participação nas atividades políticas e de liberdade de associação, inclusive afiliação a partidos políticos e sindicatos; [...]. 191. Medidas que os partidos políticos devem adotar: a) considerar a possibilidade de examinar a estrutura e os procedimentos dos partidos a fim de eliminar todas as barreiras que discriminem direta ou indiretamente contra a participação da mulher; b) considerar a possibilidade de estabelecer iniciativas que permitam às mulheres participar plenamente em todas as estruturas internas de tomada de decisões e nos processos de nomeação por designação ou eleição; c) considerar a possibilidade de incorporar as questões de gênero em seu programa político, adotando medidas para garantir a participação das mulheres na direção dos partidos políticos em pé de igualdade com os homens [...] (ONU, 1995)
}

Resenha Eleitoral (Florianópolis), v. 23, n. 1, p. 187-212, 2019 
Prontamente, houve uma mobilização por parte de parlamentares e ativistas brasileiras para que algumas ações fossem implementadas a tempo das eleições de 1996. Isso culminou com a aprovação da Lei n. 9.100, em 29 de setembro de 1995, que instituiu a cota mínima de 20\% para candidaturas femininas aos partidos políticos (PIMENTEL FILHO; RODRIGUES, 2017, p. 131-133; MELO, 2018).

Apesar da grande novidade que a lei impôs, ela encerrou duas sutis artimanhas que acabaram por reduzir o impacto concreto dessa norma, quais sejam: (a) o número de candidaturas passou de 100\% do número de vagas a preencher no parlamento para $120 \%$ (o que, na prática, praticamente não exigiu que os partidos reduzissem as candidaturas masculinas naquele pleito); e (b) o limite a ser preenchido por candidatas mulheres $(20 \%)$ tinha como referência o número máximo de candidaturas a serem registradas abstratamente, ou seja, se houvesse 10 cargos em disputa, como o partido poderia inscrever 12 candidatos, era obrigado a deixar 3 vagas reservadas para mulheres (já que 3 vagas é o número inteiro que corresponde a 20\% de 12 vagas). Ou seja, o partido poderia lançar 9 homens e nenhuma candidata mulher e, ainda assim, estaria respeitando as vagas reservadas às mulheres, nos termos da lei. É por essa razão que se referem à norma como se ela tivesse um caráter opcional (RODRIGUES, 2017, p. 31).

Em 30.9.1997, com a promulgação da lei que deveria ser a Lei Geral das Eleições, a Lei n. 9504, esse percentual foi ampliado para 30\% (art. 10, \ $3^{\circ}$ ), tendo sido igualmente ampliado para 150\% o número de candidatos que poderiam ser registrados por partidos políticos ou coligações. Portanto, o mesmo problema resultante da política de reserva de candidaturas acabou por reduzir o estímulo legal ao preenchimento de vagas por candidatas mulheres, dada a sua facultatividade.

Somente com a edição da Lei n. 12.034/2009 é que o ordenamento jurídico brasileiro passou a adotar mecanismos um pouco mais incisivos, destinados à promoção da participação feminina na política mediante: (a) a inclusão de um comando obrigatório aos partidos para que inscrevessem um percentual minimo de candidaturas femininas nos pleitos eleitorais (alteração da redação do $\int 3^{\circ}$ do art. 10 da Lei das Eleições, quando a expressão "de- 
verá reservar"4 foi substituída pela expressão "preencherá"5; (b) a determinação de que os partidos devessem destinar um percentual mínimo (5\%) dos recursos recebidos do fundo partidário para empregar em "programas de difusão e de participação feminina na política" (inclusão do inc. V ao art. 44 da Lei n. 9096/95), sob pena de ter que acrescer ao montante de 5\% (art. 44, inc. V) o equivalente a $2,5 \%$ dos recursos a serem recebidos no exercício subsequente (inclusão do $\int 5^{\circ}$ ao art. 44 da Lei n. 9096/95); e, ainda, (c) o dever de incluir espaço na "propaganda partidária gratuita de rádio e televisão" (art. 45 da Lei n. 9096/95) o equivalente a 10\% do tempo total destinado aos partidos para promoverem e difundirem a participação política feminina (inclusão do inc. IV ao art. 45 da Lei n. 9096/95).

É justamente em face da inclusão de mecanismos de estímulo à participação em três facetas distintas (candidaturas, propaganda partidária e financiamento de programas de fomento) que se costuma referir a essa norma como aquela que teria instituído, efetivamente, uma política de ação afirmativa de proteção e incentivo à participação política da mulher (PIMENTEL FILHO; RODRIGUES, 2017, p. 137).

Especificamente em relação ao tema a ser abordado neste artigo científico, a redação inicial do inciso V do art. 44 da Lei n. 9096/95 previa que os recursos oriundos do Fundo Partidário fossem aplicados

(...) na criação e manutenção de programas de promoção e difusão da participação política das mulheres conforme percentual que será fixado pelo órgão nacional de direção partidária, observado o mínimo de $5 \%$ (cinco por cento) do total.

Em acréscimo, a própria norma previu ainda uma forma de sancionamento aos partidos que descumprissem o novo comando legal, nos seguintes termos:

$\int 5^{\circ} \mathrm{O}$ partido que não cumprir o disposto no inciso $\mathrm{V}$ do caput deste artigo deverá, no ano subsequente, acrescer o percentual de 2,5\% (dois inteiros e cinco décimos por cento) do Fundo Partidário para essa destinação, ficando impedido de utilizá-lo para finalidade diversa."

\footnotetext{
${ }^{4}$ Art. 10, $\int$ 3: "Do número de vagas resultante das regras previstas neste artigo, cada partido ou coligação deverá reservar o mínimo de trinta por cento e o máximo de setenta por cento para candidaturas de cada sexo".

5 "Do número de vagas resultante das regras previstas neste artigo, cada partido ou coligação preencherá o mínimo de 30\% (trinta por cento) e o máximo de $70 \%$ (setenta por cento) para candidaturas de cada sexo".
} 
Este comando legal prescrevia uma conduta positiva ("destinação dos recursos"), direcionada à satisfação de uma finalidade pré-definida (“criação e manutenção de programas de formação e difusão da participação feminina”), acrescida de dispositivo específico ( $\left(5^{\circ}\right)$ que prescrevia sanção (acrescer o percentual de 2,5\% do Fundo Partidário para essa destinação) e proibia expressamente comportamento diverso ("fica impedido de aplicá-lo em finalidade diversa").

No entanto, este mecanismo específico foi substancialmente alterado pela minirreforma eleitoral de 2015 (Lei n. 13.165/15), promulgada no contexto da necessidade de adaptação da legislação eleitoral à proibição de financiamento empresarial dos partidos e das campanhas eleitorais (DIAS; VIEIRA, 2017, p. 123).

Se, por um lado, a redação do inc. V do art. 44 foi mantida quase incólume, somente com o acréscimo sobre o órgão partidário responsável pela definição das políticas e programas (no caso, ou a Secretaria da Mulher ou o Instituto/Fundação de Pesquisa respectivo); por outro, a alteração do $\int 5^{\circ}$ e a inclusão dos $\iint 5^{\circ}-\mathrm{A}$ e 7 ㅇ representaram fatores de desestímulo à implementação da política afirmativa prevista no inciso V. E, mais do que isso, representaram autêntica autorização legislativa para que os partidos políticos aplicassem os referidos recursos para finalidades distintas da prevista no referido dispositivo (art. 44 , inc. V).

O novo $\int 5^{\circ}$ do art. 44 passou a ser redigido nos seguintes termos:

$\int 5^{\circ} \mathrm{O}$ partido político que não cumprir o disposto no inciso $\mathrm{V}$ do caput deverá transferir o saldo para conta específica, sendo vedada sua aplicação para finalidade diversa, de modo que o saldo remanescente deverá ser aplicado dentro do exercício financeiro subsequente, sob pena de acréscimo de 12,5\% (doze inteiros e cinco décimos por cento) do valor previsto no inciso $\mathrm{V}$ do caput, a ser aplicado na mesma finalidade.

Este dispositivo acaba por reduzir a carga semântica de obrigatoriedade dos partidos de destinarem os recursos financeiros para os referidos programas, porquanto:

(a) o dispositivo legal autorizou que as agremiações partidárias não utilizassem, no próprio exercício financeiro, os recursos que por força legal deveriam ser empregados na implementação dos referidos programas, desde que destinassem o saldo remanescente à "conta específica"; 
(b) a norma revogou a multa inicialmente prevista (de 2,5\% do fundo partidário do exercício seguinte) às agremiações que não tivessem empregado os recursos naquele exercício financeiro;

(c) a norma passa a exigir que os recursos não utilizados naquele exercício fossem aplicados no exercício subsequente, situação esta que, caso não se realizasse, importaria na aplicação de multa somente no próximo exercício, com percentual reduzido.

Nessa última hipótese, a norma passou a prever multa de 12,5\%, o que, à primeira vista, pode parecer um aumento da sanção imposta ao partido $^{6}$. No entanto, o que ocorreu foi uma significativa redução da multa a ser aplicada à agremiação, porque a sanção originária $(2,5 \%)$ era calculada sobre a totalidade dos recursos a serem recebidos do fundo partidário (o que resultaria em um acréscimo de 5 para 7,5\% da destinação destes). Com a nova regra, além do fato de que a aferição de descumprimento teria que ser feita em relação ao exercício seguinte (dificultando a sistemática de controle de sua efetiva utilização), esses $12,5 \%$ passaram a ser calculados sobre os valores que, correspondentes a $5 \%$ do fundo partidário repassado dois anos antes, deveriam ter sido empregados em programas de fomento à participação feminina. Ou seja, a multa foi reduzida de $2,5 \%$ para $0,625 \%$ do fundo partidário (12,5\% sobre 5\%) (CEPIA, 2018, p. 34).

A situação é ainda mais dramática quando se analisam os $\$ \int 5^{\circ}-\mathrm{A}$ e 7ำ acrescidos ao art. 44 da Lei dos Partidos Políticos, em que se pode

\footnotetext{
${ }^{6}$ Sob esse aspecto, Rodrigues (2017, p. 41-42) defende que essa proporção (12,5\%) é calculada sobre o valor do Fundo Partidário, e seria o somatório dos 5\% do exercício anterior, cuja falta de repasse causou a penalidade de 2,5\%, somados aos 5\% do exercício atual em que ela foi aplicada. Nas palavras do autor, a proporção "equivale aos primeiros 5\% não gastos, mais os 5\% do ano subsequente, somados aos 2,5\% de sanção". Segundo o autor, ainda, isso teria se dado para compensar uma possível falha da Lei 12.034/09 que não teria obrigado o uso do saldo remanescente não utilizado, junto ao valor da sanção e dos respectivos 5\% do exercício atual, o que não corresponde ao entendimento do TSE. Nesse sentido, cita-se um trecho da decisão da Corte na Prestação de Contas 23507/DF, referentes ao exercício de 2012, quando vigia, portanto, a Lei 120.034/09 e foi determinado o uso do saldo remanescente, bem como de quaisquer valores vinculados aos mesmos fins que forem devidos: "b) Cumprimento da obrigação legal relativa à destinação mínima de 5\% do total do Fundo Partidário para incentivo à participação feminina na política, devendo destinar o remanescente de $\mathrm{R} \$ 132.722,52$, acrescido de 2,5\% dos recursos do Fundo Partidário de 2012, corrigidos monetariamente, no exercício seguinte ao deste julgamento, sem prejuízo dos valores para iguais fins que forem devidos no respectivo exercício".
}

Resenha Eleitoral (Florianópolis), v. 23, n. 1, p. 187-212, 2019 
observar que é a lei que autoriza seu desvirtuamento pelos partidos políticos. Os referidos dispositivos legais encontram-se enunciados nos seguintes termos:

$\int 5$-A. A critério das agremiações partidárias, os recursos a que se refere o inciso $V$ poderão ser acumulados em diferentes exercícios financeiros, mantidos em contas bancárias específicas, para utilização futura em campanhas eleitorais de candidatas do partido.

$\int 7^{\circ}$ A critério da secretaria da mulher ou, inexistindo a secretaria, a critério da fundação de pesquisa e de doutrinação e educação políti$\mathrm{ca}$, os recursos a que se refere o inciso $\mathrm{V}$ do caput poderão ser acumulados em diferentes exercícios financeiros, mantidos em contas bancárias específicas, para utilização futura em campanhas eleitorais de candidatas do partido, não se aplicando, neste caso, o disposto no $\int 5^{\circ}$.

Desta forma, a um só tempo, a lei autorizou que, em relação a estes recursos, os partidos políticos:

(a) aplicassem-nos no financiamento de campanhas eleitorais de candidatas do partido (sem qualquer fixação de limites para sua utilização, o que poderia envolver a totalidade dos recursos previstos para serem aplicados em programas, nos termos do inc. V do art. 44); e, ainda,

(b) a critério dos órgãos partidários (Secretaria da Mulher ou do Instituto/ Fundação de Pesquisa), os acumulassem em diversos exercícios financeiros sucessivos sem que fosse aplicada a sanção prevista no $\ 5^{\circ}$ (a multa de $0,625 \%$ na hipótese de eles não serem utilizados no tempo fixado no novo $\int 5^{\circ}$ ).

Como foi posteriormente declarado pelo Supremo Tribunal Federal, através de expressa autorização legal, os partidos foram estimulados a aplicarem os recursos destacados do fundo partidário em finalidade distinta daquela reservada pela Lei n. 12.034/2009 (inc. V do art. 44).

Não se quer com isso deixar de reconhecer que a destinação dos recursos às campanhas eleitorais de candidatas certamente pode ter sido importante (quiçá, decisiva) para inúmeras candidaturas nos pleitos de 2016 e 2018. Inclusive, há de se reconhecer que uma das formas mais eficazes de fomentar a participação das mulheres na política é alocar recursos (públicos) para suas campanhas.

No entanto, ao agir dessa forma, a lei (e os partidos) acabam por contribuir para a consolidação de um círculo vicioso de perpetuação de uma condição de subalternidade no papel desempenhado pelas mulheres, 
nos partidos e na cena política. Dessa forma, sem que sejam implementados programas e políticas voltadas à formação e à visibilização das mulheres no interior de suas agremiações, persistirá a dificuldade de encontrar mulheres "competitivas", aptas a se lançarem nos pleitos eleitorais (a despeito de todas as dificuldades próprias do mundo masculinizado da política partidária $)^{7}$.

Como já mencionado anteriormente, em 25.10.2016, o Ministério Público Federal ajuizou a Ação Direta de Inconstitucionalidade n. 5.617/DF, por meio da qual impugnou especificamente o art. 9ำ da Lei n. 13.165/15, que fixava os limites mínimo e máximo de 5\% e 15\% do FP para financiamento de campanha de mulheres, bem como limitava o uso de tal reserva por somente três eleições.

Apesar da ação ter se insurgido originariamente somente contra este dispositivo específico criado pela Lei n. 13.165/2015, a partir da intervenção da CEPIA (Cidadania, Estudo, Pesquisa, Informação e Ação), associação civil vinculada à Escola de Direito da Fundação Getúlio Vargas no Rio de Janeiro, na condição de amicus curiae, o STF não se limitou a enfrentar a compatibilidade do referido texto legal em face da garantia constitucional de igualdade (em sentido substantivo), mas emprestou interpretação aditiva ao dispositivo legal (para exigir a destinação às candidaturas femininas de percentual não inferior a 30\% do total dos recursos do fundo partidário destinados às campanhas eleitorais) e, ainda, declarou a inconstitucionalidade por arrastamento dos $\iint 5^{\circ}-\mathrm{A}$ e $7^{\circ}$ do art. 44 da Lei n. $9.096^{8}$.

\footnotetext{
${ }^{7}$ As candidaturas femininas já são as que possuem tanto menos recursos quanto capacidade de arrecadá-los, pois as mulheres infelizmente não costumam ser vistas por financiadores de campanha como nomes de êxito ou vitoriosos num pleito eleitoral (ALVES, 2018, p. 101).

8 "O Tribunal, por maioria e nos termos do voto do Relator, julgou procedente a ação direta para: i) declarar a inconstitucionalidade da expressão "três", contida no art. 9o da Lei 13.165/2015, eliminando o limite temporal até agora fixado; ii) dar interpretação conforme à Constituição ao art. 9o da Lei 13.165/2015 de modo a (a) equiparar o patamar legal mínimo de candidaturas femininas (hoje o do art. 10, \ 3ํㅡㄹ da Lei 9.504/1997, isto é, ao menos 30\% de cidadãs), ao mínimo de recursos do Fundo Partidário a lhes serem destinados, que deve ser interpretado como também de 30\% do montante do Fundo alocado a cada partido, para as eleições majoritárias e proporcionais, e (b) fixar que, havendo percentual mais elevado de candidaturas femininas, o mínimo de recursos globais do partido destinados a campanhas lhe seja alocado na mesma proporção; iii) declarar a inconstitucionalidade, por arrastamento, do \5-A e do \ 7ํㅡㄹ do art. 44 da Lei 9.096/1995 [...] Plenário, 15.03.2018.”
} 
Em seu parecer, então, a CEPIA apresentou o argumento ao STF de que os referidos dispositivos legais permitiam a confusão entre os recursos, com sua consequente diminuição, duplamente, tanto em relação ao fomento dos programas de incentivo à mulher na política, quanto dos mecanismos de financiamento de suas campanhas eleitorais (CEPIA, 2018, p. $34-36 ; 41-43)^{9}$.

Em 27.09.2018, o Supremo Tribunal Federal aceitou o pedido de modulação dos efeitos da inconstitucionalidade por arrastamento dos $\iint 5^{\circ}$ A e 7ำ, apesar de não ter acatado um pedido de embargos de declaração interposto pela Câmara dos Deputados por sua extemporaneidade (proposto antes da publicação do acórdão). De acordo com essa decisão, proferida às vésperas do primeiro turno das eleições gerais de 2018, foi considerada regular a utilização dos recursos nas campanhas femininas daquele ano, desde que tivessem, até àquela data, sido acumulados conforme as regras então vigentes.

Assim se pronunciou a Corte Suprema, quanto à questão:

O Tribunal, por maioria, modulou os efeitos temporais da decisão para, exclusivamente em relação à declaração de inconstitucionalidade por arrastamento do $\int 5^{\circ}-\mathrm{A}$ e do $\int 7^{\circ}$ do art. 44 da Lei 9.096, acrescidos pela Lei 13.165, assegurar que, sem que haja a redução de

\footnotetext{
${ }^{9}$ Nas palavras do Relator Min. Edson Fachin em seu voto sobre a questão, a qual foi seguida pela maioria dos colegas: "Pelas razões até aqui apresentadas, também deve ser julgado procedente o pedido formulado pelo CEPIA para a declaração de inconstitucionalidade por arrastamento do disposto no art. 44, $\int 5^{\circ}-\mathrm{A}$ e $\int 7^{\circ}$. $[\ldots]$ Em relação aos $\int 5^{\circ}-\mathrm{A}$ e $\int 7^{\circ}$, a discricionariedade conferida, quer às agremiações partidárias, quer às secretarias da mulher, autorizaria-lhes, em tese, a utilizar os recursos destinados à promoção e difusão da participação política das mulheres em suas campanhas, como se tal obrigação estivesse em seu âmbito de discricionariedade. É preciso reconhecer que ao lado do direito a votar e ser votado, como parte substancial do conteúdo democrático, a completude é alcançada quando são levados a efeito os meios à realização da igualdade. Só assim a democracia se mostra inteira. Caso contrário, a letra Constitucional apenas alimentará o indesejado simbolismo das intenções que nunca se concretizam no plano das realidades. A participação das mulheres nos espaços políticos é um imperativo do Estado e produz impactos significativos para o funcionamento do campo político, uma vez que ampliação da participação pública feminina permite equacionar as medidas destinadas ao atendimento das demandas sociais das mulheres. Há ainda muito a se fazer. [...] Daí porque a atuação dos partidos políticos não pode, sob pena de ofensa às suas obrigações transformativas, deixar de se dedicar também à promoção e à difusão da participação política das mulheres" (Inteiro Teor do Acórdão, p. 25-26)
} 
$30 \%$ do montante do fundo alocado a cada partido para as candidaturas femininas, os recursos financeiros de anos anteriores acumulados nas contas específicas de que cuidam esses dispositivos sejam adicionalmente transferidos para as contas individuais das candidatas no financiamento de suas campanhas eleitorais no pleito geral de 2018, nos termos do voto do Relator [...] Plenário, 3.10.2018.

Dessa forma, o próprio Supremo Tribunal Federal acabou por estabelecer uma regra de transição, tendo em vista o princípio da anualidade eleitoral, o que, na prática, postergou os efeitos da declaração de inconstitucionalidade por arrastamento dos $\iint 5^{\circ}-\mathrm{A}$ e $7^{\circ}$, para momento subsequente ao do pleito que se avizinhava. Afinal, uma decisão que se propunha a resguardar a ação afirmativa para o fomento da participação da mulher na política não poderia prejudicar aquelas que haviam se candidatado ao pleito de 2018 e que contavam com os recursos oriundos dessa fonte de financiamento.

Importante ainda destacar que a decisão proferida na ADI 5.617DF, apesar de ter sido julgada no dia 15.03.2019, só teve o seu acórdão publicado em 3.10.2019, há apenas quatro dias do primeiro turno das eleições. Período em que estes recursos já haviam sido gastos segundo a forma até então prevista pela Lei n. 13.165/15.

Apesar de a decisão do STF não ter o condão de repristinar a redação original da Lei n. 12.034/2009 em sua totalidade, ela extirpou da ordem jurídica a faculdade conferida ao partido de política de escolher entre a efetiva aplicação desses recursos nos programas definidos no inc. V (do art. 44 da Lei n. 9096/95) e a reserva e subsequente aplicação dos mesmos em campanhas eleitorais de mulheres.

Ainda sob o impacto da alteração no desenho institucional inicialmente previsto pelas agremiações partidárias para a distribuição dos recursos públicos de financiamento de campanhas, profundamente alterado em razão das decisões do STF (ADI n. 5617/DF, de 15.3.2018) e TSE (Consulta $\mathrm{n}^{\circ}$ 0600252-18, de 22.5.2018), o Congresso Nacional editou a Lei n. 13.831/2019 que disciplinou regras de transição quanto à aplicabilidade das penalidades às agremiações partidárias em face do descumprimento da regra prevista no art. 44, inc. V da Lei dos Partidos Políticos.

Em face dessas normas, inúmeras entidades da sociedade civil organizada manifestaram-se publicamente em repúdio ao que qualificaram como anistia geral aos partidos políticos pelo descumprimento do art. 44, inc. 
V da Lei n. 9096/95. Antes de enfrentar especificamente esse argumento, na última seção deste artigo, serão analisados detidamente os dispositivos incluídos pela recentíssima norma legal (os arts. 55-A, 55-B e 55-C, acrescentados ao título das disposições gerais e transitórias da Lei n. 9096/95).

\section{As alterações da Lei n. 13.831/2019 e a (suposta) "anistia" aos partidos políticos}

A Lei n. 13.831/2019 foi promulgada como uma espécie de reação dos partidos políticos contra determinadas exigências fixadas pelo Tribunal Superior Eleitoral, substancialmente, em relação ao prazo de duração das comissões provisórias (Res. TSE n. 23.571, de 29.5.2018), às exigências de prestação de contas e de escrituração de dados impostas às agremiações partidárias, inclusive, àquelas sem movimentação financeira (Res. TSE n. 23.464, de 17.12.2015), à extensão da responsabilização individual dos dirigentes partidários e a determinadas imputações fixadas contra os partidos políticos em processos de prestação de contas (art. $2^{\circ}$ e $3^{\circ}$ da Lei n. 13.831, de 17.5.2019).

Para os fins deste artigo, serão tratadas especificamente as regras de transição que foram acrescentas pelo art. $2^{\circ}$ ao título de disposições finais e transitórias da Lei dos Partidos Políticos, que dizem respeito à situação de partidos que não utilizaram adequadamente os recursos para os programas de incentivo às mulheres na política. Após sua entrada em vigor, diversas notícias foram veiculadas na mídia em geral anunciando a suposta anistia conferida, bem como o suposto retrocesso determinado pela sua entrada em vigor, o que foi corroborado por alguns especialistas que opinaram sobre a questão ${ }^{10}$.

\footnotetext{
${ }^{10}$ Dentre as manifestações, destaca-se o parecer contrário ao PL 1.321 feito pela associação sem fins lucrativos "Visibilidade Feminina", que tem por finalidade fomentar o protagonismo das mulheres nos espaços de poder público (ASSOCIAÇÃO VISIBILIDADE FEMININA, 2019), a nota conjunta da Comissão Nacional da Mulher Advogada, da Comissão Especial de Estudo da Reforma Política e da Comissão Especial de Direito Eleitoral do Conselho Federal da OAB (2019), a nota de repúdio do Movimento de Combate à Corrupção Eleitoral (MCCE), que idealizou a Lei da Ficha Limpa (NEVES, 2019), bem como a entrevista concedida pela Dra. Roberta Gresta e pelo Dr. Fernando Neisser ao jornalista Leonardo Sakamoto (SAKAMOTO, 2019).
} 
Antes de analisar especificamente os argumentos dirigidos contra estes dispositivos legais, nesta seção pretende-se tão-somente definir o escopo e o propósito dos artigos 55-A, 55-B e 55-C.

O primeiro deles, o art. 55-A, encontra-se descrito nos seguintes termos:

Os partidos que não tenham observado a aplicação de recursos prevista no inciso $\mathrm{V}$ do caput do art. 44 desta Lei nos exercícios anteriores a 2019, e que tenham utilizado esses recursos no financiamento das candidaturas femininas até as eleições de 2018, não poderão ter suas contas rejeitadas ou sofrer qualquer outra penalidade.

A partir de simples leitura, pode-se concluir sem maiores dificuldades que tal dispositivo legal se refere, especificamente, a uma espécie de inclusão na lei do que foi preceituado pelo STF, quando julgou os Embargos de Declaração na ADI n. 5.617-DF e autorizou a utilização dos recursos reservados para o fomento de campanhas eleitorais femininas "até as eleições de 2018".

O que se tem aqui é uma espécie de cláusula de segurança prevista pelo Congresso Nacional, como forma de prevenir os partidos políticos contra eventuais interpretações futurais por parte da Justiça Eleitoral que flexibilizem, ou, ainda, que venham a mitigar o alcance da manipulação dos efeitos da decisão proferida pelo STF, quando do julgamento dos Embargos de Declaração. Notadamente, em razão da decisão pouco ortodoxa proferida pela Corte Suprema quando, apesar de rejeitar os aclaratórios interpostos, decidiram por preservar os recursos que, reservados na forma do $\int 5^{\circ}-\mathrm{A}$, haviam sido destinados a candidaturas femininas nos pleitos de 2016 e 2018.

Já com relação ao art. 55-B, o mesmo dispõe que:

Art. 55-B. Os partidos que, nos termos da legislação anterior, ainda possuam saldo em conta bancária específica conforme o disposto no $\int 5^{\circ}$-A do art. 44 desta Lei poderão utilizá-lo na criação e na manutenção de programas de promoção e difusão da participação política das mulheres até o exercício de 2020, como forma de compensação.

A regra em questão não guarda maior dificuldade interpretativa. Ela pode ser qualificada como autêntica regra de transição, porquanto admite que, excepcionalmente, os valores remanescentes na conta corrente espe- 
cífica mencionada no $\int 5^{\circ}-\mathrm{A}$ (declarado inconstitucional pelo STF) possam ser usados para além do atual exercício de 2019 sem a sanção cominada no \5 $5^{\circ}$ (de $12,5 \%$ sobre $5 \%$ do FP, ou seja, 0,625\% sobre o FP de 2018).

A fim de evitar quaisquer mal-entendidos quanto ao alcance dessa regra, de forma a conferir-lhe aplicação conforme o texto constitucional, impõe-se delimitar a abrangência da expressão "como forma de compensação" definida no final desse dispositivo.

Quando a norma se refere a isso, não está a autorizar que a agremiação partidária reduza do montante de $5 \%$ do fundo partidário mediante compensação de recursos não utilizados em exercícios pretéritos. O que se está a mitigar é o tempo previsto pela lei para aplicar (utilizar) esses recursos. Em outras palavras, excepcionalmente, a norma previu que as agremiações que não conseguirem dispender todos esses recursos durante este exercício (de 2019), poderiam aplicá-lo ao longo de 2020.

Portanto, a expressão "como forma de compensação" jamais pode ser interpretada como uma forma de compensação de valores que serão destinados pelos partidos aos programas de fomento à participação feminina.

Por fim, o art. 55-C é o que, sem sombra de dúvidas, tem suscitado mais críticas e demanda um olhar um pouco mais acurado sobre o seu alcance. O dispositivo encontra-se descrito nos seguintes termos: "Art. 55-C. A não observância do disposto no inciso V do caput do art. 44 desta Lei até o exercício de 2018 não ensejará a desaprovação das contas”.

A norma estabelece dois comandos muito claros:

a) que a simples não observância do disposto no inc. V do art. 44 não pode ensejar, por si só, a rejeição das contas da grei partidária; e

b) que essa interpretação, fixada pela lei, deve prevalecer em relação a todas as contas partidárias em processamento perante a Justiça Eleitoral, até, inclusive, as contas partidárias referentes ao exercício de 2018.

Diferentemente do que vem sendo criticado, defende-se neste artigo que não se está diante de uma anistia geral aos partidos políticos que não tenham destinado adequadamente o montante de $5 \%$ dos recursos do fundo partidário para as despesas com promoção e fomento da participação feminina na política. 
A fim de afastar quaisquer compreensões inadequadas sobre o alcance deste dispositivo, considerando ainda a falta de estudos técnicos relacionados ao tema, defende-se neste artigo científico que:

(a) a regra em discussão se limita a consolidar um entendimento vigente no âmbito do Tribunal Superior Eleitoral até o início do ano de 2019, que a não utilização dos recursos do art. 44, inc. V da Lei n. 9.096/95 não era considerada grave o suficiente para, por si só, ensejar a rejeição das contas anuais da agremiação partidária;

(b) tendo em vista a preocupação por parte dos partidos políticos em conferirem previsibilidade às (futuras) decisões da Justiça Eleitoral, a regra estabelece um marco temporal (qual seja, o exercício de 2018) até quando a interpretação até então vigente (consubstanciada no texto legal de acordo com o qual essa irregularidade não pode ser considerada grave suficiente à rejeição das contas) deve ser observada pela Justiça Eleitoral; e

(c) essa regra deve ser interpretada de forma restritiva, ou seja, ela não pode ser aplicada de maneira a impedir toda e qualquer forma de descumprimento ao disposto no art. 44, inc. V.

Esta última consideração (c) exige algumas precisões adicionais.

A lei não visa proteger toda e qualquer forma de descumprimento da obrigação legal, ou seja, ela não poderia anistiar os partidos políticos que, eventualmente, tenham destinados recursos financeiros desta conta corrente para financiar campanhas eleitorais masculinas, seja através de repasses diretos, seja através de usos indiretos por intermédio de candidaturas laranja. Da mesma forma que a norma não isenta de punição agremiações partidárias que tenham se valido de simulação ou fraude para a utilização indevida de recursos originariamente destinados ao fomento de programa de formação de mulheres.

Assim, apesar do aparente efeito simbólico de perdão aos partidos políticos, que em muitos casos sistematicamente não se esforçam para destinar os recursos para a finalidade prevista, segundo se defende aqui, a Lei n. 13.831/19 não realizou qualquer anistia geral aos partidos políticos inadimplentes. Muito pelo contrário, nesse aspectos, a norma se limitou a conferir segurança jurídica aos administrados, veiculando interpretação autêntica (porque produzida pela via legislativa) destinada à proteção dos princípios constitucionais da segurança jurídica, da proteção da confiança e, ultima ratio, do princípio da anualidade da legislação eleitoral. 
Diante disso, discorda-se da visão de que o objetivo da Lei n. 13.831/19 foi de anular as conquistas da importante ação afirmativa de destinar e garantir recursos ao fomento da participação da mulher na política, bem como de "anistiar e premiar" os partidos políticos que não realizaram os repasses, conforme opinaram a Dra. Roberta Gresta e o Dr. Fernando Neisser, em entrevista conjunta ao jornalista Leonardo Sakamoto (2019).

Nesse sentido também se posicionaram a Comissão Nacional da Mulher Advogada, a Comissão Especial de Direito Eleitoral e a Comissão Especial de Estudo da Reforma Política da Ordem da Advocacia Brasileira. Em nota conjunta, reforçaram a pecha de que a Lei n. 13.831/19 teria promovido uma "anistia" aos partidos e um retrocesso na política de ações afirmativas em prol de maior participação feminina na política, acusando-a ainda de ter "clara intenção de tornar a Lei n. 13.165/2015, e todo o avanço que representou, letra morta". Conforme visto, foram justamente as alterações promovidas pela Lei n. 13.165/15 que causaram, em verdade, uma anistia aos partidos e um real retrocesso nas conquistas estabelecidas pela Lei n. 12.034/09, no que diz respeito, ao menos, ao repasse para os programas de fomento.

Também a Associação sem fins lucrativos "Visibilidade Feminina" (2019, p.22), em parecer sobre o tema, alegou que a inserção dos arts. 55-A, 55-B e 55-C na Lei n. 9096/95 isentou os partidos políticos de suas responsabilidades e caracterizou um "regresso nas tratativas legais das questões referentes às políticas em prol do aumento da participação feminina”, posição da qual, conforme todo exposto, reitera-se, distancia-se.

\section{Direito sancionador eleitoral, segurança jurídica, devido processo legal e a rejeição de contas por violação ao art. 44, V, da Lei n. 9.096/99}

Como quaisquer outras sanções aplicadas pela Justiça Eleitoral às agremiações partidárias decorrentes do descumprimento de regras legais, as punições advindas de irregularidade na aplicação de recursos devem igualmente ser compreendidas como exercício do jus puniendi estatal e, como tal, ensejam a aplicação daquilo que, em outra oportunidade, convencionou-se chamar como direito sancionador eleitoral (CUNHA, 2019, p. 59) ${ }^{11}$.

${ }^{11}$ Frederico Franco Alvim (2019, p. 135) também se utiliza de expressão semelhante, qual seja "direito eleitoral sancionador", para classificar o ramo ao qual pertencem todos os ilícitos eleitorais, sem, entretanto, debruçar-se sobre o conceito. 
O direito sancionador eleitoral pode ser qualificado como um ramo do contencioso eleitoral que visa à apuração de uma conduta antijurídica em face da qual o Estado aplica uma sanção que pode consistir na imposição de uma obrigação de conduta (facere ou non facere), na cominação de sanção pecuniária, na imputação de uma medida restritiva de direitos (entre as quais se destacam as inelegibilidades) e/ou, ainda, na cassação de um registro ou de um mandato resultante do exercício de sufrágio eleitoral (CUNHA, 2019, p. 50).

Como todo processo de natureza sancionatória, o contencioso eleitoral voltado à apuração da imputação de condutas qualificadas como ilícitos eleitorais exige a estrita observância de garantias processuais ínsitas ao devido processo legal, sob pena de grave malversação de um dos pilares da ordem constitucional vigente, inerente à regra de ouro do Estado de Direito. Mormente, quanto mais severas são as sanções passíveis de serem aplicadas aos imputados, tanto mais efetivas devem ser as garantias de defesa que lhes devem ser asseguradas. Isso porque tais ilícitos, em que pese não estarem previstos como crimes, em muitas situações preveem sanções mais severas que outras cominadas aos ilícitos penais eleitorais, assim como, em diversos contextos, protegem bens jurídicos semelhantes em seu grau de importância ao adequado funcionamento das regras do jogo democrático.

Diante disso, defende-se como premissa teórica neste artigo, que não há (ou não deveria haver) diferenças substanciais no que diz respeito ao regime de produção probatória, de ampla defesa e contraditório, do direito a um recurso eficaz e à segurança jurídica e demais garantias inerentes ao devido processo legal para imputação de sanções.

Ao qualificar que a aplicação de uma sanção (no caso, a rejeição de contas com subsequente suspensão do recebimento das cotas do fundo partidário, na forma do art. 37 da Lei n. 9096/95; e, ainda, a aplicação de multa, na forma do $\int 5^{\circ}$ do art. 44 da mesma lei) se insere no âmbito do direito sancionador eleitoral, está a se reclamar que deva ser aplicado aos partidos políticos (e aos dirigentes e gestores subjetivamente responsáveis pelas irregularidades a que deram causa, nos termos do $\int 14$ do art. 37 da Lei 9096/95), um conjunto de garantias processuais próprias desse ramo do direito (ÁLVAREZ GONZALEZ, 2009; VÁZQUEZ RANGEL, 2012; ROSETTE SOLÍS, 2012) $)^{12}$.

${ }^{12}$ Em estudo ampliado realizado em sede de monografia, a temática da natureza sancionatória dos ilícitos eleitorais e a individualização e caracterização do direito sancionador eleitoral, 
Segundo já apontado brevemente, o entendimento que o TSE adotava, de maneira reiterada até o início de 2019, em relação às contas prestadas pelos órgãos de direção dos três níveis federativos (nacional, estadual e municipal), em relação ao descumprimento do art. 44, inc. V da Lei dos Partidos Políticos, era de que o descumprimento dessas regras, por si só, não se revestia de gravidade suficiente a ensejar a rejeição das contas daquele órgão.

A título meramente ilustrativo, colaciona-se o seguinte trecho de aresto exarado pelo TSE, in verbis:

EMBARGOS DE DECLARAÇÃO. PRESTAÇÃO DE CONTAS. PARTIDO ECOLÓGICO NACIONAL (PEN). EXERCÍCIO FINANCEIRO DE 2012. IRREGULARIDADE SUPRIDA. APRESENTAÇÃO DE DOCUMENTOS EM SEDE DE EMBARGOS. POSSIBILIDADE. APROVAÇÃO COM RESSALVAS. [...] 2. Remanesce apenas a irregularidade referente à não aplicação minima de recursos do Fundo Partidário na criação e manutenção de programas de promoção e difusão da participação política das mulheres, consoante previsto no inciso $V$ do art. 44 da Lei no 9.096/95, o que, por si só, não enseja a desaprovação das contas. 3. Embargos de declaração acolhidos, com efeitos infringentes, para aprovar com ressalvas as contas do partido. (Prestação de Contas no 23167, Acórdão, Relator(a) Min. Luciana Lóssio, Publicação: DJE - Diário de justiça eletrônico, Tomo 53, Data 18/03/2015, Página 17-18) (grifo nosso)

Assim, a sanção aplicada em decorrência do descumprimento por parte da agremiação partidária da efetiva aplicação das verbas referentes aos programas de participação feminina na política restringia-se à aplicação da multa de 2,5\% do fundo partidário no exercício subsequente, orientação jurisprudencial que estava consolidada e em plena vigência até o final de $2018^{13}$.

Entretanto, em abril deste ano, a Corte deu uma guinada jurisprudencial, passando a dar um tratamento diferenciado à questão. Durante o julgamento das contas referentes ao ano de 2013, o TSE passou a entender

bem como algumas premissas teóricas para a construção de um modelo processual compatível, foram desenvolvidas de forma mais aprofundada (CUNHA, 2019, p. 48-74).

${ }^{13}$ Nesse sentido, o julgamento das Prestações de Contas n. 24381/DF-19962/DF-23337DF-22815/DF-23507/DF-23859/DF-21516/DF-20217/DF-23689/DF-22645/DF$24295 / \mathrm{DF}$. 
que a violação sistemática por parte da agremiação dessa regra deveria ensejar a reprovação das contas. É o que se extrai do julgamento da Prestação de Contas n. 31971/DF, cuja ementa segue.

PRESTAÇÃO DE CONTAS ANUAL. EXERCÍCIO FINANCEIRO DE 2013. AVANTE (EX-PT do B). RECURSOS DO FUNDO PARTIDÁRIO. DESPESAS IRREGULARES. DEFICIÊNCIA. DOCUMENTAÇÃO. DESAPROVAÇÃO. 1. Trata-se de prestação de contas do exercício financeiro de 2013 do Diretório Nacional do Avante. [...] 9. A legenda descumpriu o percentual minimo de 5\% - art. 44, $V$, da Lei 9.096/95 - para programas de incentivo à participação feminina na política ao não comprovar gastos de $R \$ 136.560,05$. A norma vem sendo reiteradamente desobedecida pela grei desde o exercício de 2009, circunstância que, por si só, autoriza rejeitar o ajuste contábil (nesse sentido, PC 292-88, Rel. Min. Og Fernandes, sessão de 28.3.2019) [...] 13. Contas do Diretório Nacional do Avante desaprovadas, determinando-se: a) recolhimento ao erário de R\$107.255,64 (verbas do Fundo Partidário aplicadas de modo irregular); b) suspensão de novas cotas por um mês, a ser cumprida de forma parcelada em duas vezes, após o trânsito em julgado; c) aplicação de $2,5 \%$ a mais de recursos, no exercício seguinte ao trânsito em julgado desta decisão, para promover a mulher na política (art. 44, V e \ 5º, da Lei 9.096/95). (Prestação de Contas nº 31971, Acórdão, Relator(a) Min. Jorge Mussi, Publicação: DJE - Diário de justiça eletrônico, Data 31/05/2019) ${ }^{14}$

Diante deste cenário, fica claro que o legislador, ao inserir os dispositivos 55-A, 55-B e 55-C à Lei 9096/95, reagiu às decisões do TSE e o fez, em nosso entender, acertadamente. Isso porque se está, conforme delimitado, diante de manifestação do direito sancionador eleitoral, devendo-se observar, reitera-se, a segurança jurídica e as regras do devido processo legal. Além do que uma mudança na interpretação, conforme prescreve o próprio art. 23 da Lei de Introdução às Normas do Direito Brasileiro ${ }^{15}$, não se pode projetar retroativamente.

\footnotetext{
${ }^{14}$ Nesse sentido, também, os julgamentos das Prestações de Contas n. 30320/DF-29021/ DF-29288/DF e 28329/DF.

15 "A decisão administrativa, controladora ou judicial que estabelecer interpretação ou orientação nova sobre norma de conteúdo indeterminado, impondo novo dever ou novo condicionamento de direito, deverá prever regime de transição quando indispensável para que o novo dever ou condicionamento de direito seja cumprido de modo proporcional, equânime e eficiente e sem prejuízo aos interesses gerais."
} 
As decisões proferidas deveriam, ao contrário, ter deixado claro que a nova interpretação valeria a partir de 2019, permitindo, assim, que os partidos alterassem efetivamente a sua forma de agir no tocante à implementação dos programas de participação feminina na política.

\section{Considerações finais}

A partir de todo exposto, demonstra-se a necessidade de reflexão sobre os limites do exercício do poder sancionatório do Estado, expresso através da Justiça Eleitoral no contexto de um direito sancionador eleitoral. A ansiedade e a recalcitrância do Poder Legislativo em consolidar políticas de ação afirmativa tão relevantes, reforçada por uma prática excludente, machista e antidemocrática dos partidos políticos, não pode ensejar que o Poder Judiciário caia na tentação de substituir a esfera política.

Especificamente em relação às anistias determinadas pela Lei $\mathrm{n}$. 13.831/19, apesar de se reconhecer que há um elemento simbólico negativo, impulsionado por eventuais más compreensões sobre o seu alcance. Os dispositivos aqui analisados, os artigos 55-A, 55-B e 55-C, concretizam adequadamente os valores da segurança jurídica e da preservação do devido processo legal, imprescindíveis em se tratando de exercício do jus puniendi do Estado.

Com relação ao art. 55-A, tem-se a garantia legal do que foi decidido no julgamento dos Embargos de Declaração da ADI n. 5.617. Com o art. 55-B, tem-se uma regra de transição que permite que os partidos gastem as reservas para além do exercício subsequente (no caso, as reservas acumuladas até 2018 poderiam ser gastas ao longo de 2019 e 2020); desde que a expressão "como forma de compensação" seja interpretada neste sentido (de mitigação no tempo) e não como forma de redução dos valores mínimos fixados pelo art. 44, inc. V da Lei n. 9.504/97.

Por fim, no que diz respeito ao polêmico art. 55-C, ele também concretiza a garantia constitucional da segurança jurídica quando garante que a interpretação fixada pelo TSE, até abril de 2019, seja aplicada a todas as prestações de contas referentes aos exercícios financeiros anteriores ao ano de 2018. Portanto, ele não impede a apuração e punição de outras fraudes e ilegalidades relacionadas ao uso dos recursos previstos no art. 44, V da Lei n. 9096/95.

Outrossim, com relação à anistia conferida, esta realmente se deu não com a Lei n. 13.831/19, mas sim com as disposições da Lei n. 13.165/15. Uma lei que vergonhosamente traz, em seu preâmbulo, o pro- 
pósito de "incentivar a participação feminina", mas instituiu um conjunto de mecanismos que promoveram exatamente o seu oposto: estímulos para que os partidos desviem a finalidade dos recursos vinculados à ação afirmativa de promoção da participação feminina na política, conquistas instituídas pela Lei n. 12.034/09.

Não se quer, com isso, diminuir a importância da preservação das conquistas das mulheres e da necessidade de resistência frente aos ataques sistemáticos às conquistas aqui obtidas. $\mathrm{O}$ ambiente com o qual a mulher se depara na política é um ambiente hostil e cercado de empecilhos que visam mantê-la afastada, de modo a preservar o status quo do perfil masculino, branco, heterossexual, cristão e proprietário à frente dos assuntos públicos do país. Mas entende-se que o combate ao machismo estrutural tão presente em todos os setores da sociedade, mais ainda nas instituições políticas, não pode se dar com o esvaziamento das garantias da segurança jurídica e das regras do devido processo legal, sendo ressaltado com o aumento do já problemático protagonismo do Poder Judiciário neste cenário.

É preciso levar a sério as políticas de ação afirmativa em prol da participação da mulher na política. Mas também é preciso levar a sério as regras que sustentam o Estado de Direito e o equilíbrio entre as instituições, valores fundamentais para o sustento e o avanço da própria democracia.

\section{Referências}

ÁLVAREZ GONZÁLEZ, Juan Manoel. Alguns principios del derecho penal sustativo aplicables al derecho sancionador electoral. p. 17-46. In: E1 ilicíto y su castigo: reflexiones sobre la cadena perpetua, la pena de muerte y laidea de sanción en el derecho / David Cienfuegos Salgado - México: Editora Laguna: Fundación Académica Guerrerense: Universidad Autónoma de Guerrero, Maestría en Derecho Público, Universidad Autónoma de Sinaloa, Unidad de Posgrado en Derecho, 2009. 348p.

ALVES, Yanne Katt Teles Rodrigues. Debatendo a representatividade: um panorama histórico e breve reflexão sobre a participação feminina na política brasileira. Revista Estudos Eleitorais, Recife, V.2, N. 3, p. 95-103, jul. 2018.

ALVIM, Frederico Franco. Abuso de poder nas competições eleitorais. Curitiba: Juruá, 2019. 408p. 
ASSOCIAÇÃO VISIBILIDADE FEMININA. Parecer técnico-jurídico Projeto de Lei n. 1.321/2019: Sobre a proposta de inserção dos arts. 55-A, 55-B e 55-C à Lei 9096 de 1995. Disponível em: https:/ /www.conjur.com.br/ dl/parecer-visibilidade-feminina-duracao.pdf. Acesso em: 16 abr. 2019.

CEPIA (Cidadania, Estudo, Pesquisa, Informação e Ação). Memorial como amicus curiae na Ação Direta de Inconstitucionalidade n. 5.617. Disponível em: http:/ / redir.stf.jus.br/paginadorpub/paginador.jsp?docTP=TP\&docID $=683051478 \&$ prcID $=5080398$. Acesso em: 13 set. 2017 .

COELHO, Gabriela. Publicada lei que anistia partidos por não cumprir cota feminina. Disponível em: https://www.conjur.com.br/2019-mai-20/ publicada-lei-anistia-partidos-nao-cumprir-cota-feminina. Acesso em: 20 maio 2019.

CUNHA, Amanda Guimarães da. De player político a árbitro no direito sancionador eleitoral: o resgate do dever de imparcialidade do julgador a partir das garantias convencionais. 2019. 135fls. Monografia - Universidade do Vale do Itajaí, SC.

DIAS, Willian Silva; VIEIRA, Murilo Braz. Os custos com as campanhas eleitorais à luz da reforma eleitoral de 2015 (Lei n. 13.165/2015). Revista Estudos Eleitorais. Volume 12, Número 3, setembro/dezembro de 2017. Em nota, comissões classificam como retrocesso anistia a partidos políticos que não se comprometem com participação feminina. Disponível em: https://www.oab.org.br/noticia/57205/em-nota-comissoes-classificam-como-retrocesso-anistia-a-partidos-politicos-que-nao-se-comprometem-com-participacao-feminina. Acesso em: 19 maio 2019.

INTER-PARLIAMENTARY UNION. Women in national parliaments. February 2019. Disponível em: http://archive.ipu.org/wmn-e/ClaSSif.htm. Acesso em: 15 de jul. 2019.

MELO, Hilda Pereira de. A política de cotas para as mulheres no Brasil: importância e desafios para avançar! Disponível em: http://www.generonumero.media/a-politica-de-cotas-para-as-mulheres-no-brasil-importancia-e-desafios-para-avancar/. Acesso em: 13 set. 2018.

NEVES, Rafael. Movimento da Ficha Limpa critica aprovação de projeto que beneficia dirigentes partidários. Disponível em: https:/ congressoemfoco.uol.com.br/especial/noticias/movimento-da-ficha-limpa-critica-aprovacao-de-projeto-que-beneficia-dirigentes-partidarios/. Acesso em: 28 mar. 2019. 
PIMENTEL FILHO, José Ernesto; RODRIGUES, Mariana Ramos. A política legislativa e a proteção à participação política da mulher: uma interpretação histórica de processos legislativos. Revista A Barriguda. Campina Grande, 7 [1], p. 127-149, jan.-abr. 2017.

Ranking de presença feminina no Poder Executivo - PMI 2018. Março de 2018. Projeto Mulheres Inspiradoras. Disponível em: http://urlmaster. com.br/ctratk/marlene-campos-machado/Ranking-de-Presença-Feminina-no-Poder-Executivo-2018.pdf. Acesso em: 10 jul. 2019.

RODRIGUES, Ricardo José Pereira. A evolução da política de cota de gênero na legislação eleitoral e partidária e a sub-representação feminina no parlamento brasileiro. Revista Eletrônica Direito e Política, Programa de Pós-Graduação Stricto Sensu em Ciência Jurídica da UNIVALI, Itajaí, v.12, n.1, $1^{\circ}$ quadrimestre de 2017. Disponível em: www.univali.br/direitoepolitica - ISSN 1980-7791. Acesso em: 15 jul. 2019.

ROSETTE SOLÍS, Bertha Leticia. Naturaleza jurídica del derecho electoral sancionador: algunas consideraciones en torno al Libro Quinto del Código de Instituciones y Procedimientos Electorales del Distrito Federal Tribunal Electoral del Distrito Federal. Mexico, 2012. Disponível em: https://www.tecdmx.org.mx/files/326/publicaciones/varias/naturaleza_juridica.pdf. Acesso em: 01 maio 2019.

SAKAMOTO, Leonardo. Congresso e Presidência atestam machismo com anistia, dizem especialistas. Disponível em: https://blogdosakamoto. blogosfera.uol.com.br/2019/05/21/congresso-e-presidencia-atestam-machismo-com-anistia-dizem-especialistas/. Acesso em: 21 maio 2019.

VAZQUEZ RANGEL, Osíris. Derecho sancionador electoral y principio de legalidade. Electio Revista Especializada del Tribunal Electoral del Distrito Federal. Num. 2, Jun-Dic 2012. Primera edición, Diciembre 2012. p. 37-60. Disponível em: https://www.tecdmx.org.mx/files/326/publicaciones/ electio/02_electio.pdf. Acesso em: 01 maio 2019.

\section{Fontes documentais}

BRASIL. Supremo Tribunal Federal. Ação Direta de Inconstitucionalidade n. 5.617. Acórdão. Relator Ministro Edson Fachin. DJU - Diário de Justiça Eletrônico, 19 de março de 2019. 
Tribunal Superior Eleitoral. Prestação de Contas n⿳ํㅡㄹ 23167, Acórdão, Relator(a) Min. Luciana Lóssio, Publicação: DJE - Diário de justiça eletrônico, 18 de março de 2015.

. Tribunal Superior Eleitoral. Prestação de Contas nº 31971, Acórdão, Relator(a) Min. Jorge Mussi, Publicação: DJE - Diário de justiça eletrônico, 31 de maio de 2019.

Tribunal Superior Eleitoral. Estatísticas do eleitorado por sexo e faixa etária. Disponível em: http://www.tse.jus.br/eleitor/estatisticas-de-eleitorado/estatistica-do-eleitorado-por-sexo-e-faixa-etaria. Acesso em: 16 jul. 2019.

ORGANIZAÇÃO DAS NAÇÕES UNIDAS. Declaração e plataforma de ação da IV Conferência mundial sobre a mulher. 1995. Disponível em: http://www.onumulheres.org.br/wp-content/uploads/2014/02/declaracao_ pequim.pdf. Acesso em: 16 jul. 2019.

Amanda Guimarães da Cunha - Especialista em Ciências Penais pela Uniderp, Bacharel em Direito pela Universidade do Vale do Itajaí (UNIVALI), Membro Pesquisador do Observatório do Sistema Interamericano de Direitos Humanos (UNIVALI) nas áreas de direitos humanos, gênero, direito penal e processual penal, direito eleitoral e processual eleitoral.

Luiz Magno Pinto Bastos Junior - Pós-Doutor pelo Centro de Direitos Humanos e Pluralismo Jurídico da Universidade McGill (Montreal, Canadá). Doutor e Mestre em Direito pela Universidade Federal de Santa Catarina (UFSC). Graduado em Direito pela Universidade Federal do Pará (UFPA). Professor do Programa de Mestrado e Doutorado em Ciência Jurídica da Universidade do Vale do Itajaí (UNIVALI) e das disciplinas de Direito Constitucional, Direito Eleitoral e Direitos Humanos no curso de Graduação em Direito. Advogado militante nas áreas de direito eleitoral e direito administrativo (Sócio do Escritório Menezes Niebuhr Advogados Associados). Membro fundador da Academia Brasileira de Direito Eleitoral e Político (ABRADEP) e Academia Catarinense de Direito Eleitoral (ACADE). Coordenador do Observatório do Sistema Interamericano de Direitos Humanos (UNIVALI). 